\title{
Library suggestions and typologies of information needs
}

\author{
Andrew K. Shenton
}

\begin{abstract}
This paper explores the strengths and weaknesses of investigating information needs through scrutiny of library suggestions made by users. The method is attractive in drawing upon material that many libraries collect routinely and which may be used to present a picture of need that cannot easily be gained through other techniques. Nevertheless, insights achieved via suggestions analysis typically relate only to the library itself and often to its perceived weaknesses. There are ethical questions surrounding the use of suggestions data out of context, and researchers cannot know in advance that sufficient data relevant to their information needs focus will be elicited. Investigators must also decide on their stance regarding the wider applicability of their findings. Despite all these issues, suggestions data can play a pivotal role in inspiring the development of subsequent research into information needs, and may have considerable value when used in concert with other methods.
\end{abstract}

\section{Introduction}

In the history of research into information behaviour a wide variety of methods has been employed to explore people's information needs. In addition to the longestablished techniques of interviews and questionnaires, which involve the collection of data directly from individuals with regard to their needs, various "inferential" approaches have been taken. These have included the use of figures devoted to the relative numbers of books borrowed in particular subject sections within a library collection and the maintenance, again in libraries, of logs recording queries. Attempts have also been made to gain an understanding of the information needs of those in a particular group via the application of appropriate theories of human development and existing literature relating to their more general needs and problems. The lack of a widely agreed framework based either on a single technique or a combination of several reflects the difficulty of conducting an effective investigation into people's information needs. Acknowledging it to be a challenging task, Devadason and Pratap Lingam describe the process of identifying information needs as "one of the 'grey areas'

\section{Author}

Dr. Andrew K. Shenton is a former Lecturer in the Division of Information and Communication Studies at Northumbria University.

E-mail: ashenton1@hotmail.com 
of research in library and information science for the past few decades" (Devadason and Pratap Lingam, 1997, 42).

In view of the diversity of methods that have been employed and their lack of universal acceptance, it is perhaps surprising that very little effort appears to have been made to construct typologies of information needs on the basis of suggestions offered by library users. Although other means that are typically employed by libraries to gather feedback, such as focus groups and panels of library users, may offer similar potential, it is paper-based and electronic suggestions systems that form the focus of this article. Suggestions systems are often established to help ensure that the library develops in a way that is broadly consistent with user inclinations. Such mechanisms also provide patrons with some ownership of decision-making processes within the library and can alert library managers to the good ideas of their clients. Moreover, where responses are given by the library to suggestions, they enable staff to provide generic answers to patrons who raise similar issues. One possible explanation for the rarity with which data elicited via suggestions systems have been employed to construct systematic pictures of users' needs, lies in a possible mismatch between the priorities of library managers and those of researchers exploring information needs. The former's aims in introducing suggestions mechanisms may well be practical in nature and directly concerned with the service offered by the library, whereas, notwithstanding the potential of the investigation of information needs within the context of action research, many projects addressing such needs are predominantly scholarly, with the work undertaken by students for assignments and dissertations or by academics outside the library environment intent on publishing their studies in journals or presenting them at conferences.

In any project involving information needs, before the researcher chooses methods for collecting data consideration must be given to what will be meant in the work by the use of such fundamental terms as information and information needs. Decisions in this regard provide the study with some preliminary ground rules and help to clarify the boundaries of the phenomena under investigation as they are understood in the project. Clearly, it is the responsibility of each individual researcher, or research team, to form these definitions with due attention to their own situations and, perhaps, the type of library involved. An investigator in a library associated with an educational organisation, for example, may well give special emphasis to the scholarly information needs of users. Indeed, Eskola (1998), whose work relates to university students, defines information as "something which students need during their studies when they construct meaning about subjects in the process of learning". In generic terms for the purposes of this paper, however, information is believed to take the form of "communicated messages that convey meaning" (Shenton, 2004a, 370), and, in the context of information needs, such material is required by a person "to ease, resolve or otherwise address a situation arising in his or her life" (Shenton and Dixon, 2004a, 26). Information may, for example, be needed to alleviate an anxiety, make a decision, develop a greater understanding, find out about a subject or solve a problem. 


\section{Principal attractions of the method}

Much of the appeal of devising an investigation into information needs that draws on user suggestions centres on the ready availability of this form of data. This is a factor not to be underestimated since, as Nicholas recognises, in many other situations

needs data is difficult to collect. The researcher must step into a world beyond their control, persuade and seek co-operation, ask (often personal) questions for which there are no stereotypical responses, and probe for data in unfamiliar territory (Nicholas, 1997, 344).

In contrast, libraries of a range of types provide on an everyday basis means by which users can offer feedback through suggestions, and the data contributed may be considered significantly more "natural" than that gathered from questionnaires or interviews, which are more specifically associated with research and which consequently may be viewed by users with some suspicion. Openness and honesty may be particularly forthcoming in user suggestions if anonymity is permitted.

The freedom that suggestions systems give to users in enabling them to state the information that they feel they actually require may also liberate them from their possible perception that they should express their needs in terms that are appropriate to the library. In a classic paper, Taylor (1968) draws attention to how a query presented to an information system is influenced by the inquirer's expectation of what is available. Taylor describes such a need as "compromised" (Taylor, 1968, 182). The "mutation" of the need from its original form is a significant problem when efforts are made to infer information needs from reference questions that are asked by users. Since, when offering a suggestion, the writer is not bound by the limitations of the information system, there is, perhaps, more opportunity for the person to present their need in a manner which reflects more accurately their real requirement.

The ideas of even primary school children in relation to their school library can be collected successfully through suggestions systems. At this level, strategies may include the use of a proforma which offers sentences that the youngsters complete, thereby helping the children to structure their ideas or directing their suggestions to particular areas. The prompts have to be carefully constructed, however. When research reported by the Department of Education and Science used an approach in which primary-aged youngsters were asked to complete a sentence beginning, "I wish there were more books about..." (Department of Education and Science, 1983, 16), eighteen children believed that the sentence was already finished and simply agreed with the statement!

If a variety of channels is offered for suggestions feedback, data may be elicited from a diversity of types of user. In an academic library, for example, the opportunity to make suggestions electronically, possibly via a proforma offered by the library's website, may be welcomed by distance learners who may use the library mainly for providing a gateway to e-journals, whilst the chance to make comments via a more traditional pencil and paper method may be preferred by some campus-based students. 


\section{Disadvantages}

As with the use of library issue figures for information needs research, the employment of suggestions in this respect is limited by the fact that, notwithstanding the ability of suggestions data to uncover the real needs of individuals, users will undoubtedly present these needs in terms of their reactions to the library's characteristics. This overall orientation contrasts markedly with the doctrine favoured by Faibisoff and Ely who declare unequivocally, "Studies of needs should concentrate on needs rather than on the system supplying the needs" (Faibisoff and Ely, 1976, 5). Furthermore, in many situations, it may not be the needs of actual users that form the paramount concern; what is maybe more important is the needs of the wider community which the library is attempting to serve, and users may form only a fraction of this body.

Suggestions systems frequently elicit messages of dissatisfaction and complaint, and the picture that emerges from them is likely to be largely negative. Indeed, suggestions mechanisms may be criticised for encouraging hot-headed reactions from users immediately after they have experienced adverse situations. There is also the danger, particularly with teenagers in a school library, that suggestions offered by disaffected individuals may simply be criticisms of authority. Furthermore, if suggestions do merely reflect dissatisfaction with the library, the ideas contributed may well be as much expressions of wants as actual needs, although, as Shenton and Dixon (2004b) note, LIS commentators have for years debated the precise differences between the two concepts. In contrast, needs that the library satisfies adequately are seldom expressed. This problem is indicative of a wider difficulty associated with information needs research. Whilst Derr recognises that "possession of information does not eliminate the need for it" (Derr, 1983, 273), the needs which are met via that material may not be easily uncovered. Research based on suggestions also entirely disregards the now widely-recognised phenomena of "unexpressed needs" and "dormant needs". Even when a person is aware of a need having emerged and seeks to act upon it, "the problem of non-specifiability of information need", as discussed by Belkin $(1980,137)$, may arise. Suggestions systems are unlikely to be useful in exploring the situations described by Belkin (ibid.) in which an individual "is conscious of a need but does not know what information would be appropriate to satisfy it".

Critical of the way in which the traditional research methods of interviews and questionnaires themselves affect the attitudes that they are intended to examine, Webb et al advocate a strategy involving the inconspicuous analysis of evidence "generated without the producer's knowledge of its use by the investigators" (Webb et al, 2000, 49-50). Clearly, the key consideration in helping to secure the success of a suggestions system as an unobtrusive research method lies in ensuring that the users contributing ideas are not aware that their material is to be used for research purposes. The same principle may be applied to the employment of query logs to explore information needs. Nevertheless, the ethics of such a covert research method in the context of library suggestions are open to question, and issues associated with establishing "informed consent" arise. It may be argued that, if reports of studies of user needs are to be compiled and then disseminated beyond the library, via conference papers or journal articles, for example, and such work refers to the personal situations of participants, even if all the data are 
anonymised, contributors should be made aware of what is intended in advance of their offering suggestions. Otherwise, they may be under the mistaken impression that it is only library staff and, in particular, perhaps, senior management, who will be reading their ideas.

The employment of suggestions data for information needs investigation is maybe best applied retrospectively, yet, in these circumstances, the task of obtaining consent for using suggestions that have already been made is particularly problematic. If a researcher designs a study which will examine the nature of the suggestions over a stipulated future period, he or she becomes a hostage to fortune. Because no attempt is made to collect data from a sample of predetermined size, it may be that insufficient suggestions will be offered over the period earmarked for data collection to satisfy the study aims. Conventional research methods can also suffer from this shortcoming, however. If a questionnaire-based project meets with a poor response or if in a study involving interviews many people within the targeted group decline to talk to the researcher, the work may be hampered by a similar lack of data. Where a retrospective orientation is adopted and records of past suggestions have been retained, the researcher may select a period of sufficient length to ensure that enough suggestions have been made to suit the purposes of the project. The analysis strategy then employed essentially shifts to one of making a content assessment of existing documents.

If users are allowed to make suggestions on any aspect of the library that they wish, the contributions are likely to be very diverse and analysis of such disparate data can be challenging. Again, though, this is not a problem that is by any means unique to suggestions data. The analysis of data collected in a rambling focus group session, in which the moderator has failed to direct the discussion sufficiently, can prove equally difficult. Still, if suggestions data are to be used exclusively for needs research, researchers may find it wise to rein in contributors by giving specific advice, prior to suggestions being made, on particular areas that they may wish to address. Suggestions may be sought, for example, on what particular types of information and materials users want to see increased in provision and what new information services may be especially welcomed. Such direction may effectively screen out many suggestions that may otherwise be offered but which do not pertain to information needs issues. Without such channelling, suggestions may take the form of complaints about, for example, heating, staffing, photocopying provision and opening hours, although the last two matters may be considered at least to relate broadly to information access, if not information needs. Conversely, the danger again emerges that, where very strict guidance is given on the types of issues that should be raised in the suggestions, insufficient data may be collected to meet the purposes of the research. Where such a possibility is likely, strategies to promote the suggestions system vigorously, and the need for the library to convince its users that managers will take notice of any ideas offered, assume an added importance.

\section{Wider use of suggestions-based research}

In terms of the wider use of research based on suggestions data, a range of approaches may be taken. Since the suggestions made are likely to be very 
particular to the library involved and perhaps to the users who are served, the extent to which the study findings are generalisable in the traditional sense is probably limited. The aim of transferability may be more viable. If the report presenting the results of research involving the suggestions data will be read by parties beyond the library, then the provision of background description relating to the characteristics of the organisation in question is essential. Managers of another library, for example, who are reading the report are likely to be particularly interested in such details in order that they may compare the situation of the library forming the subject of the research with that of their own organisation. Ultimately, if they are satisfied that sufficient similarity exists between what Lincoln and Guba term the "sending" and "receiving" contexts $(1985,217)$, readers may feel encouraged to make transferability inferences with confidence.

Where further projects based on suggestions data are staged in additional libraries, progress in other aspects of wider applicability can be made. The findings of each study may be compared in order to ascertain the extent to which a consistent picture is apparent overall. In this way, the original project comes to form one element within what may be considered a multi-site case study of sorts and, where findings are repeated across different sites, statements regarding transferability may be made with more assurance, as well as the results of the original investigation having more credibility in the eyes of the reader. Hjørland believes that, in the positivist tradition, such replicability forms the "methodological ideal" (Hjørland, 2002, 264). Certainly, as Shenton (2004b) points out, in any study that involves several organisations, the effect of particular local factors peculiar to only one of them is reduced. The sampling of a range of libraries provides the kind of diversity that underpins Dervin's concept of "circling reality", which she defines as

the necessity of obtaining a variety of perspectives in order to get a better, more stable view of 'reality' based on a wide spectrum of observations from a wide base of points in time-space (Dervin, 1983, 7).

Where findings that relate to different libraries diverge, the investigator may seek to explain these via variations in the libraries' characteristics and those in the users whom they serve.

One approach to selecting the organisations for the follow-up work may involve sampling other comparable local libraries. Alternatively, the organisations may be determined on the basis of principles advanced by Yin (1994). He indicates that a researcher undertaking a multiple-case study may use "literal replication" and "theoretical replication" (Yin, 1994, 46). In the former, cases are chosen in the belief that examination of them will yield similar results, and, in the latter, cases are selected on the grounds that contrasting findings will emerge, although for predictable reasons. According to Yin, if six to ten cases which, in their entirety, embrace both forms of replication logic are explored and they all produce the results anticipated, the researcher's initial propositions have been vindicated. If, however, the researcher has no interest in the information needs of users beyond his or her own library, then replication of the project in other organisations is not, of course, an issue. 


\section{Qualitative or quantitative?}

Whilst most techniques for investigating user needs may be regarded as inherently qualitative or quantitative, research based on library suggestions does not fit easily in either category. Nevertheless, it does meet some of the criteria associated with qualitative research. In particular, the ideas offered by contributors are expressed in their own language and in this respect the method is very different from that of questionnaires in which a multiple-choice answer arrangement demands that users frame their ideas in the survey document's terms. In addition, when the data are analysed, if categories of need are formed in order to produce a need typology, the divisions are likely to be developed inductively from the inherent concepts within the data. Conversely, since the starting point for constructing an understanding of user needs is in this case the library, rather than the particular situation of the user, the work does not have the personal emphasis typically associated with qualitative inquiry, and there is no real opportunity to collect background detail about the nature of the contributor. Furthermore, unless the participants include their names with their suggestions, thereby allowing provision for some kind of follow-up, it is difficult even subsequently to probe the stated problems and issues in the depth that is characteristic of qualitative work. In this sense, the method suffers from a similar shortcoming to questionnaires and participant diaries, namely that because there is no real-time direct interaction between the two parties the researcher simply has to accept the material that the contributor offers and hope that he or she has supplied sufficient data for a proper impression of the need to be gained. Such shortcomings illustrate the fact that there is no single perfect method of collecting data. Banwell highlights the importance of three specific elements of contextual information which are essential for constructing "a picture of individual need" (Banwell, 1997, 71). These are devoted respectively to the user's own characteristics, the task for which the information is required and the nature of the topic. Without these insights, the adequacy of the understanding of the need may be challenged.

Data relating to information needs that have been collected via suggestions systems may be too scanty and too diverse for true quantitative analysis, too, unless the researcher develops very broad categories from the material and then attaches frequency counts on the basis of how many users have made suggestions that fall within each of the divisions. Such a strategy raises the possibility of a hybrid research approach being taken. Frequency counts are invaluable in that they provide a transparency to results, indicating the prevalence of particular issues within the data collected. Quotations from participants or at least direct descriptions of situations recounted by users can then be employed to illustrate the issues identified. Reference to such individual situations is more reminiscent of the qualitative paradigm. The combined importance of creating types within a typology and making appropriate reference to the words of the actual participants is stressed by Lofland who writes,

the abstractions [taking the form of the types] and qualitative data [taking the form of the quotations] coexist as one whole. Each depends on the other for enlightenment and meaning. Taken separately, the abstractions and data may have slight interest or merit. The abstractions are likely to be dull because the reader has an inadequate conception of the concrete, empirical reality to which 
they might refer. The qualitative data alone are dull because the reader has little notion of generic patterns involved, save those he might himself be imposing. But interpenetration through minute and continual alternation between abstraction and episodes makes the whole more than the parts (Lofland, 1976, 65).

In some instances, several typologies may, in fact, be required. Allen draws attention to how information needs "occur within groups of various kinds", as well as "at the individual level" (Allen, 1997, 112). In a university library, analysis of the data in terms of the group dimension may reveal the existence of different categories of information needs in relation to students of different types, such as undergraduates and postgraduates, campus-based and distance learners, or students straight from school and mature students. Thus, in order to ensure that the clients' particular needs are properly represented, a typology for each individual group may be necessary.

The philosophical justification for a mixed method approach that incorporates qualitative and quantitative elements is summed up by Patton, who believes the researcher to have an "intellectual mandate" (Patton, 1990, 193) for selecting whatever techniques he or she considers most suitable, regardless of their paradigm. A similar argument is presented by Grover and Fowler (1993) and Dervin (1997). Yet, although Erlandson et al (1993), Krueger (1994) and Miles and Huberman (1994) point out that such mixing has become common, this eclecticism is not shared by all and any researcher thinking of combining qualitative and quantitative data should at least be aware of the controversy in some quarters that surrounds work of this kind. Merriam writes of the "ongoing debate" (Merriam, 1998, 8) surrounding its validity, and Silverman believes that two "armed camps" (Silverman, 2000, xiii) have arisen as a result of commitments made by researchers to one or other of the paradigms. Lincoln and Guba (1985) reside firmly in the qualitative domain. In relation to naturalistic inquiry, they state unambiguously, "Mix-and-match strategies are not allowed" (Lincoln and Guba, 1985, 251), asserting that an investigator must accept the whole paradigm and all the methods it entails. Rossman and Wilson label proponents of such a stance "purists", and recognise that their steadfastness stems from a belief that qualitative and quantitative approaches derive from "different, mutually exclusive epistemological and ontological assumptions about the nature of research and society" (Rossman and Wilson, 1985, 629).

\section{Library suggestions and subsequent research data}

A reflective researcher may well question whether those making the suggestions are representative of the wider population of library users, and may suspect that people offering ideas are individuals who are particularly vociferous or have simply been unfortunate in suffering a recent adverse library-related experience. In a school library, some may be perceived to be pupils who resent authority. Conversely, others may be shy individuals, who are reluctant to discuss their concerns face-to-face with staff. A thoughtful investigator will inquire, "To what extent are the needs described typical?" Whilst the suggestions system may be significant in helping a researcher to identify individual needs or problems, a follow-up phase of quantitative investigation may be necessary to determine the prevalence, within a wider body of users, of the matters raised. Here the 
needs/problems described may be grouped and presented in a tick-box style questionnaire. Alternatively, subsequent work may take a qualitative stance. Although many users may be reluctant to offer suggestions unless they can do so anonymously, if a system is employed in which contributors are willing to provide their names alongside their ideas, there may be an opportunity for more detailed discussion, in later focus groups or individual interviews, of the emergent issues. The former are likely to be especially useful if related matters have been raised by a number of individuals, and participants for a particular group may be chosen on the basis of the similar ideas that they have already offered. Such a strategy would appear to give a focus group the greatest chance of success since, as Krueger observes, "The rule for selecting focus group participants is commonality, not diversity" (Krueger, 1994, 14). It must, however, be conceded that to introduce focus groups at such an advanced stage in the research project runs contrary to conventional practices. Marcella and Baxter note,

many researchers who have used the focus group as a methodological tool have emphasised that it should be used as a preliminary means of developing hypotheses that will be further tested by methods that allow generalisations to be drawn (Marcella and Baxter, 1999, 311).

Where detailed data on a particular phenomenon are collected, through, for example, focus groups inspired by the research involving user suggestions, subsequent investigation may shift to ascertaining the viability of different responses that the library can make in response to the emergent issue.

\section{Managing an information needs project drawing on suggestions data}

When conducting a study involving the use of suggestions data to explore users' information needs, the researcher must thus consider a variety of fundamental questions.

How will key terms, like information needs, be understood in the study?

Would it be useful to provide systems for allowing clients to submit their ideas in different ways, e.g. via paper and electronic methods?

Will the raw data used in the research take the form of suggestions made in the past or ideas that will be offered over a predetermined period in the future? If the latter option is taken, can the researcher be confident that sufficient suggestions will be collected for the project to meet its purpose?

Where a future temporal orientation is favoured, are suggestions on any aspect of the library to be encouraged or are users to be asked to restrict their ideas purely to information issues? If the latter is the case, how should such guidance be worded?

To what extent will the qualitative and quantitative potentials of the data be exploited, and how will these be achieved?

What role will other research strategies play alongside the suggestions data in contributing to a more robust investigation into users' information needs than if the suggestions data alone had been employed? 
Who will read the final report? If the results are to be disseminated beyond the library, has appropriate consent been given by the contributors of the suggestions?

What approach is to be taken with regard to transferability?

If the researcher is looking to develop a picture of information needs that extends beyond the users of the library featured in the research, is it possible for the project to be replicated in additional libraries, thereby allowing data collected in a similar way but at different places to be compared? If such replication is attempted, how will the extra libraries be chosen?

\section{Conclusions}

The ready availability of users' suggestions in many libraries is attractive to the information needs researcher and such data may be obtained from a variety of types of library visitor. Nevertheless, key shortcomings emerge and several methodological problems arise. Suggestions provide insight only into needs that relate in some way to the library and even in this context many needs that the library meets satisfactorily are likely to go unacknowledged by patrons. In order to guarantee that the researcher has sufficient material with which to work, the technique is perhaps best applied to a body of suggestions retrospectively, although the use of any suggestions data without the permission of their contributors is morally dubious. Whether a past or future orientation is taken, unless broad areas for suggestions are indicated to prospective contributors, the researcher may well discover that the data collected which pertain to information needs are outweighed by material that is irrelevant to the study. Problems associated with the generalisability of study findings may also arise but the researcher may at least be able to replicate the original project in other libraries. As Zach explains, the use of a multiple-case study can reveal "divergent themes" as well as "consistent patterns" (Zach, 2006, 19). Clearly, in the former instance, an appreciation of the reasons for such variations then emerges as a priority.

Despite the fact that suggestions data may be regarded as neither obviously qualitative nor clearly quantitative, they can be employed in both contexts and can form the inspiration for follow-up research of either type. This may be aimed quite specifically at investigating further the matters arising from the suggestions that have been received. It would, in fact, be unwise to develop an investigation into user needs based exclusively on suggestions but, when combined with other methods, such data can undoubtedly provide invaluable insights. The use of a range of techniques in concert is advocated by Devadason and Pratap Lingam who write "No single method or tool will serve entirely" (Devadason and Pratap Lingam, 1997, 42). Barrett and Douglas (2004) take a similar line in relation to client needs and school libraries. The authors stop short of elucidating a step-bystep methodology but still draw attention to how "feedback books" or "comment cards" (Barrett and Douglas, 2004, 59) can be used for needs analysis alongside data from other sources that may include student surveys, library management systems, user discussion groups, satisfaction questionnaires, socio-economic indicators and external research. These are, of course, in addition to the use of methods specifically designed to pursue discoveries from the original suggestions research itself. 


\section{References}

Allen, B. (1997) Information needs: a person-in-situation approach. In: Vakkari, P., Savolainen, R. and Dervin, B., eds. Information seeking in context, London, Taylor Graham, 111-22. ISBN 0947568719.

Banwell, L. M. (1997) Modelling user needs and the electronic age: a researcher's view. In: Watson, W. M., ed. Information and library management 2000+, Newcastle, Department of Information and Library Management, University of Northumbria at Newcastle, 67-76. ISBN 1900554119.

Barrett, L. and Douglas, J. (2004) The CILIP guidelines for secondary school libraries, London, Facet. ISBN 1856044815.

Belkin, N. J. (1980) Anomalous states of knowledge as a basis for information retrieval, Canadian Journal of Information Science 5(May), 133-43.

Department of Education and Science (1983) Aspects of school library provision and reading attitudes. London, HMSO.

Derr, R. L. (1983) A conceptual analysis of information need, Information Processing and Management 19(5), 273-78.

Dervin, B. (1983) An overview of sense-making: concepts, methods, and results to date. Paper presented at the annual meeting of the International Communications Association, Dallas, TX, May.

Dervin, B. (1997) Given a context by any other name: methodological tools for taming the unruly beast. In: Vakkari, P., Savolainen, R. and Dervin, B., eds. Information seeking in context, London, Taylor Graham, 13-38. ISBN 0947568719.

Devadason, F. J. and Pratap Lingam, P. (1997) A methodology for the identification of information needs of users, IFLA Journal 23(1), 41-51.

Erlandson, D. A. et al (1993) Doing naturalistic inquiry: a guide to methods, London, Sage. ISBN 0803949383.

Eskola, E.-L. (1998) University students' information seeking behaviour in a changing learning environment - how are students' information needs, seeking and use affected by new teaching methods? Information Research 4(2), URL: http://informationr.net/ir/4-2/isic/eeskola.html [21 April 2007].

Faibisoff, S. G. and Ely, D. P. (1976) Information and information needs, Information Reports and Bibliographies 5(5), 2-16.

Grover, R. and Fowler, S. G. (1993) Recent trends in school library media research, School Library Media Quarterly 21(4), 241-47.

Hjørland, B. (2002) Epistemology and the socio-cognitive perspective in information science. Journal of the American Society of Information Science and Technology 53(4), 257-70.

Krueger, R. A. (1994) Focus groups: a practical guide for applied research, 2nd ed., Thousand Oaks, Sage. ISBN 0803955677. 
Lincoln, Y. S. and Guba, E. G. (1985) Naturalistic inquiry, Newbury Park, Sage. ISBN 0803924313.

Lofland, J. (1976) Doing social life: the qualitative study of human interaction in natural settings, London, John Wiley and Sons. ISBN 0471015636.

Marcella, R. and Baxter, G. (1999) The citizenship information needs of the UK public: the quest for representativeness in methodological approach. In: Wilson, T. D. and Allen, D. K., eds. Exploring the contexts of information behaviour, London, Taylor Graham, 304-20. ISBN 0947568751.

Merriam, S. B. (1998) Qualitative research and case study applications in education, San Francisco, Jossey-Bass. ISBN 0787910090.

Miles, M. B. and Huberman, A. M. (1994) Qualitative data analysis: an expanded sourcebook, 2nd ed., Thousand Oaks, Sage. ISBN 0803955405.

Nicholas, D. (1997) The information needs interview: a long way from library-use statistics, Education for Information 15(4), 343-49.

Patton, M. Q. (1990) Qualitative evaluation and research methods, 2nd ed., Newbury Park, Sage. ISBN 0803937792.

Rossman, G. B. and Wilson, B. L. (1985) Numbers and words: combining quantitative and qualitative methods in a single large-scale evaluation study, Evaluation Review 9(5), 627-43.

Shenton, A. K. (2004a) Operationalising the concept of "information" for research into information behaviour, Aslib Proceedings 56(6), 367-72.

Shenton, A. K. (2004b) Strategies for ensuring trustworthiness in qualitative research projects, Education for Information 22(2), 63-75.

Shenton, A. K. and Dixon, P. (2004a) The development of young people's information needs, Library and Information Research 28(89), 25-34.

Shenton, A. K. and Dixon, P. (2004b) The nature of information needs and strategies for their investigation in youngsters, Library and Information Science Research 26(3), 296-310.

Silverman, D. (2000) Doing qualitative research: a practical handbook, London, Sage. ISBN 0761958231.

Taylor, R. S. (1968) Question-negotiation and information seeking in libraries, College and Research Libraries 29(3), 178-94.

Webb, E. J. et al (2000) Unobtrusive measures, 2nd ed., Thousand Oaks, Sage. ISBN 0761920110.

Yin, R. K. (1994) Case study research: design and methods, 2nd ed., Thousand Oaks, Sage. ISBN 0803956630.

Zach, L. (2006) Using a multiple-case studies design to investigate the information-seeking behavior of arts administrators, Library Trends 55(1), 4-21. 


\section{Acknowledgement}

The author would like to thank Dr. Susan Hayter (Adjunct Professor in the Faculty of Information and Media Studies at the University of Western Ontario) for her help in writing this paper. 